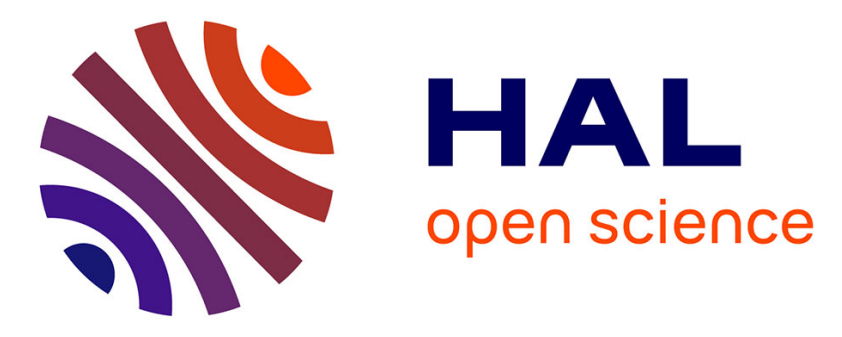

\title{
Modelling and simulations of a Monolith Reactor for three-phase hydrogenation reactions - Rules and recommendations for mass transfer analysis
}

Freddy-Libardo Durán Martínez, Carine Julcour-Lebigue, Anne-Marie Billet, Faïçal Larachi

\section{To cite this version:}

Freddy-Libardo Durán Martínez, Carine Julcour-Lebigue, Anne-Marie Billet, Faïçal Larachi. Modelling and simulations of a Monolith Reactor for three-phase hydrogenation reactions - Rules and recommendations for mass transfer analysis. Catalysis Today, 2016, vol. 273, pp. 121-130. 10.1016/j.cattod.2016.04.009 . hal-01395331

\section{HAL Id: hal-01395331 https://hal.science/hal-01395331}

Submitted on 10 Nov 2016

HAL is a multi-disciplinary open access archive for the deposit and dissemination of scientific research documents, whether they are published or not. The documents may come from teaching and research institutions in France or abroad, or from public or private research centers.
L'archive ouverte pluridisciplinaire HAL, est destinée au dépôt et à la diffusion de documents scientifiques de niveau recherche, publiés ou non, émanant des établissements d'enseignement et de recherche français ou étrangers, des laboratoires publics ou privés. 


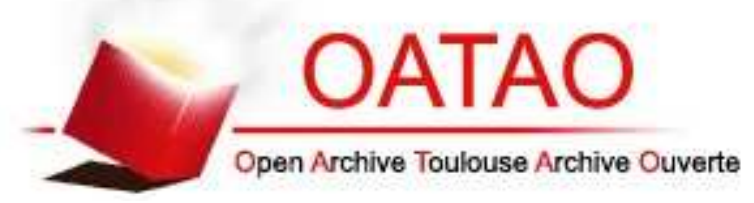

\section{Open Archive TOULOUSE Archive Ouverte (OATAO)}

OATAO is an open access repository that collects the work of Toulouse researchers and makes it freely available over the web where possible.

This is an author-deposited version published in : http://oatao.univ-toulouse.fr/ Eprints ID : 16517

To link to this article : DOI : 10.1016/j.cattod.2016.04.009

URL : http://dx.doi.org/10.1016/j.cattod.2016.04.009

To cite this version : Duran-Martinez, Freddy and Julcour-Lebigue, Carine and Billet, Anne-Marie and Larachi, Faïçal Modelling and simulations of a Monolith Reactor for three-phase hydrogenation reactions - Rules and recommendations for mass transfer analysis. (2016) Catalysis Today, vol. 273. pp. 121-130. ISSN 0920-5861

Any correspondence concerning this service should be sent to the repository administrator: staff-oatao@ listes-diff.inp-toulouse.fr 


\title{
Modelling and simulations of a monolith reactor for three-phase hydrogenation reactions - Rules and recommendations for mass transfer analysis
}

\author{
Freddy L. Durán Martínez ${ }^{\mathrm{a}}$, Carine Julcour ${ }^{\mathrm{a}}$, Anne-Marie Billet ${ }^{\mathrm{a}, *}$, Faïçal Larachi $^{\mathrm{b}}$ \\ a Laboratoire de Génie Chimique, Université de Toulouse, CNRS, INPT, UPS, 4 Allée Emile Monso, CS84234, F-31432 Toulouse, France \\ b Laval University, Chemical Engineering Department, 2325 Rue de l'Université, Québec, QC G1V 0A6, Canada
}

Keywords:

Monoliths

Catalysis

Taylor flow

Mass transfer

Simulation

\section{A B S T R A C T}

A strategy for the scale-up of a monolith reactor dedicated to gas-liquid catalytic reactions is worked out; focus is made on the crucial step of gas-liquid mass transfer modelling via a steady-state numerical study based on a single channel and single unit cell representation, using a frame moving with the bubble and solving the liquid phase only. The relevance of this simplified approach is assessed through a specific case (given bubble shape, channel diameter and fluid flow rates), and hydrodynamics as well as mass transfer results are successfully compared to previously published numerical, semi-analytical and experimental works. Influence of unit cell length and of catalytic surface reaction rate is thoroughly investigated. Inferred overall mass transfer coefficients are found to increase with bubble frequency, due to higher interfacial area in unit cell and intensified recirculation in slug. Film contribution to mass transfer is usually found dominant in the case of short bubbles with reactive wall, and hardly varies with reaction rate. However, this contribution is strongly linked to bubble frequency, and a reliable evaluation of local mass transfer by correlations demands accurate knowledge on the precise dimensions of bubble, slug and film entities.

\section{Introduction}

Chemicals and fuels are produced through catalytic gasliquid-solid reactions in a wide range of industries, including petrochemicals, fine chemicals, pharmaceuticals and biochemicals. Conventional technologies to host such gas-liquid-solid reactions are fixed-bed, slurry bubble column and fluidized-bed reactors. Slurry bubble column reactors, and fluidized beds to a lesser extent, combine three major advantages: the possibility for continuous catalyst replacement, a much reduced intra-particular diffusion path length (due to the small size of catalyst particles), and a good heat transfer efficiency. However, they suffer from some drawbacks such as liquid back-mixing, significant attrition of the catalyst and need for catalyst separation and recycling. On the other hand, despite fixed-bed reactors can be operated closer to plug flow with negligible attrition of catalyst, restrictions quickly emerge regarding soaring pressure drops which ultimately force a use of large (millimetric) particles which unavoidably imply significant

\footnotetext{
* Corresponding Author.

E-mail address: annemarie.billet@ensiacet.fr (A.-M. Billet).
}

internal diffusional limitations. In addition, the traditional cocurrent downward configuration (trickle-bed reactors) can give rise to maldistribution of the liquid resulting in catalyst partial wetting at low flow rates which render such reactors prone to hot spots inception, thus catalyst deactivation and even thermal runaway [1]. Another difficulty encountered with conventional multiphase reactors is their scale-up to industrial size units. Although these conventional reactors still play a major role in industrial processes, researchers strive looking for advantageous alternative technologies.

Structured reactors have been claimed over the past several years to offer interesting possibilities; among them, Monolith Reactors (MRs), also called 'honeycomb reactors', have been considerably studied for almost four decades as they represent a promising cutting-edge technology to circumvent the above mentioned problems enumerated in the case of conventional reactors. MRs were initially developed as catalytic converters for the automotive industry; they have been extended to include other environmental applications such as selective reductions (DeNOx catalysts) used in power plants and incinerators [2]. More recently, MRs have emerged as promising candidates competing with conventional gas-liquid-solid reactors, as they offer several advan- 


\begin{tabular}{|c|c|}
\hline \multicolumn{2}{|c|}{ Nomenclature } \\
\hline $\mathrm{a}$ & Bubble interfacial area; $\left(\mathrm{m}_{\mathrm{B}}^{2} \mathrm{~m}^{-3} \mathrm{Uc}\right)$ \\
\hline c & Concentration of dissolved gas; $\left(\mathrm{mol} \mathrm{m}^{-3} \mathrm{~L}\right)$ \\
\hline $\mathrm{c}_{\text {overall }}$ & $\begin{array}{l}\text { Volume averaged concentration, as defined in Eq. } \\
\text { (6); }\left(\mathrm{mol} \mathrm{m}^{-3} \mathrm{~L}\right)\end{array}$ \\
\hline$c_{s, \text { mean }}$ & Average slug concentration; $\left(\mathrm{mol} \mathrm{m}^{-3} \mathrm{~L}\right)$ \\
\hline$c_{\text {wall }}$ & Wall concentration; $\left(\mathrm{mol} \mathrm{m}^{-3} \mathrm{~L}\right)$ \\
\hline$c^{*}$ & Dissolved concentration at saturation; $\left(\mathrm{mol} \mathrm{m}^{-3} \mathrm{~L}\right)$ \\
\hline $\mathrm{D}$ & $\begin{array}{l}\text { Molecular diffusion of dissolved gas in the liquid } \\
\text { phase; }\left(\mathrm{m}^{2} \mathrm{~s}^{-1}\right)\end{array}$ \\
\hline$d_{B}$ & Bubble diameter; $(\mathrm{m})$ \\
\hline $\mathrm{d}_{\mathrm{c}}$ & Channel diameter; (m) \\
\hline dS & Elementary bubble surface; $\left(\mathrm{m}^{2}{ }_{\mathrm{B}}\right)$ \\
\hline $\mathrm{dV}$ & Elementary volume; $\left(\mathrm{m}^{3}\right)$ \\
\hline g & Gravity acceleration vector; $\left(\mathrm{m} \mathrm{s}^{-2}\right)$ \\
\hline $\mathrm{K}_{\mathrm{C}}$ & $\begin{array}{l}\text { Rate constant of first order surface reaction; } \\
\left(\mathrm{m}^{3} \mathrm{~L}^{-2} \text { wall } \mathrm{s}^{-1}\right)\end{array}$ \\
\hline $\mathrm{k}_{\mathrm{L}} \mathrm{a}$ & $\begin{array}{l}\text { Volumetric mass transfer coefficient; } \\
\left(\mathrm{m}^{3}{ }_{\mathrm{L}} \mathrm{m}^{-3} \mathrm{UC} \mathrm{S}^{-1}\right)\end{array}$ \\
\hline $\mathrm{L}_{\mathrm{UC}}$ & Unit cell length; $(\mathrm{m})$ \\
\hline $\mathrm{L}_{\mathrm{f}}$ & Liquid film length; (m) \\
\hline MR & Monolith reactor \\
\hline $\mathrm{N}$ & Gas molar flux, as defined in Eq. (5); ( $\left.\mathrm{mol} \mathrm{s}^{-1}\right)$ \\
\hline n & Normal vector; $(-)$ \\
\hline $\mathrm{P}$ & Pressure; $(\mathrm{Pa})$ \\
\hline$\Delta \mathrm{P}$ & Pressure drop; $(\mathrm{Pa})$ \\
\hline $\mathrm{Q}_{\mathrm{L}}$ & Volumetric flow rate; $\left(\mathrm{m}^{3} \mathrm{~s}^{-1}\right)$ \\
\hline$r$ & Radial coordinate; $(\mathrm{m})$ \\
\hline $\mathrm{R}_{\mathrm{B}}$ & Bubble radius; $(\mathrm{m})$ \\
\hline $\mathrm{U}_{\mathrm{B}}$ & Velocity of bubble center of mass; $\left(\mathrm{m} \mathrm{s}^{-1}\right)$ \\
\hline $\mathrm{U}_{\mathrm{TP}}$ & Two-phase velocity, $\mathrm{u}_{\mathrm{Gs}}+\mathrm{u}_{\mathrm{Ls}} ;\left(\mathrm{m} \mathrm{s}^{-1}\right)$ \\
\hline $\mathbf{u}$ & Velocity vector; $\left(\mathrm{m} \mathrm{s}^{-1}\right)$ \\
\hline $\mathrm{u}_{\mathrm{Gs}}$ & Superficial gas velocity; $\left(\mathrm{m} \mathrm{s}^{-1}\right)$ \\
\hline $\mathrm{u}_{\mathrm{Ls}}$ & Superficial liquid velocity; $\left(\mathrm{m} \mathrm{s}^{-1}\right)$ \\
\hline $\mathrm{u}_{\mathrm{zG}}$ & Axial component of gas velocity; $\left(\mathrm{m} \mathrm{s}^{-1}\right)$ \\
\hline $\mathrm{u}_{\mathrm{zL}}$ & Axial component of liquid velocity; $\left(\mathrm{m} \mathrm{s}^{-1}\right)$ \\
\hline $\mathrm{V}_{\mathrm{L}}$ & Liquid volume; $\left(\mathrm{m}^{3} \mathrm{~L}\right)$ \\
\hline $\mathrm{V}_{\mathrm{UC}}$ & Unit cell volume; $\left(\mathrm{m}^{3} \mathrm{UC}\right)$ \\
\hline$z$ & Axial coordinate; $(\mathrm{m})$ \\
\hline \multicolumn{2}{|c|}{ Greek symbols } \\
\hline$\varepsilon_{\mathrm{G}}$ & Gas hold-up; (-) \\
\hline$\delta_{f}$ & Film thickness; (m) \\
\hline$\mu_{G}$ & Gas dynamic viscosity; (Pa s) \\
\hline$\mu_{\mathrm{L}}$ & Liquid dynamic viscosity; (Pa s) \\
\hline$\rho_{\mathrm{L}}$ & Liquid density; $\left(\mathrm{kg} \mathrm{m}^{-3}\right)$ \\
\hline$\sigma$ & Surface tension; $\left(\mathrm{N} \mathrm{m}^{-1}\right)$ \\
\hline \multicolumn{2}{|c|}{ Dimensionless Groups } \\
\hline $\mathrm{Ca}$ & Capillary number, $\frac{\mu_{L} U_{B}}{\sigma} ;(-)$ \\
\hline $\operatorname{Re}$ & Reynolds number, $\frac{\rho_{L} U_{B} d_{c}}{\mu_{I}} ;(-)$ \\
\hline $\operatorname{Re}_{\mathrm{G}}$ & Superficial gas Reynolds number, $\frac{\rho_{G} u_{G s} d_{c}}{\mu_{G}} ;(-)$ \\
\hline $\operatorname{Re}_{\mathrm{L}}$ & Superficial liquid Reynolds number, $\frac{\rho_{L} u_{L S} d_{C}}{\mu_{L}} ;(-)$ \\
\hline $\mathrm{Sc}_{\mathrm{L}}$ & Liquid Schmidt number, $\frac{\mu_{L}}{\rho_{L} D} ;(-)$ \\
\hline $\mathrm{Sh}_{\mathrm{L}}$ & Liquid Sherwood number, $\frac{k_{L} d_{c}}{D} ;(-)$ \\
\hline
\end{tabular}

tages, e.g., the catalytic layer deposited on the wall of the numerous MR channels is thin enough (ca. $10 \mu \mathrm{m}$ ) to minimize internal diffusional resistances; the channels host specifically tunable gas-liquid flow regimes (chief among them the so-called Taylor or train bubble or slug flow), which can prove particularly convenient in terms of mass transfer interfacial area; pressure drop in MR is low; fluids flow freely avoiding reactor fouling and clogging and limiting the occurrence of hot spots; MRs offer the opportunity to perform efficient reaction heat removal through the monolith backbone provided that it is built in highly heat-conducting material.

Many works have been dedicated to the study of MR operation where the literature reports experimental studies of fluid distribution into the channels of monolith blocks [3-6], flow regimes inside the channels [7-10], and mass transfer between gas and liquid phases over the entire apparatus $[11,12]$. The overall volumetric gas-liquid mass transfer coefficient, $\mathrm{k}_{\mathrm{L}} \mathrm{a}$, was reported to be much larger in MR operating in the Taylor flow regime $\left(0.1-1 \mathrm{~s}^{-1}\right)$ $[11,13,14]$ than in stirred tanks $\left(0.03-0.4 \mathrm{~s}^{-1}\right)$, bubble columns $\left(0.005-0.25 \mathrm{~s}^{-1}\right)$ or packed beds $\left(0.004-1 \mathrm{~s}^{-1}\right)$ [15]. This enhanced mass transfer was attributed to the existence of a thin liquid film (a few tens of $\mu \mathrm{m}$ ) between the bubble and the channel wall, as well as to the efficient convective mixing within the liquid slugs provided they are short enough [16]. Of practical interest, it was shown that $\mathrm{k}_{\mathrm{L}}$ a values measured in MR correlate rather well with those predicted from single-channel models [11,14]. Indeed, most of the experimental and theoretical works on gas-liquid mass transfer have been devoted to single millimetric capillaries [12,16-23]. The relative contributions of bubble caps and lubricating film to the gasliquid mass transfer were discussed more specifically, though the conclusions were mainly drawn for non-reactive systems where likelihood of film saturation with the transferring species drastically jeopardizes such level of discrimination. In such a situation, transfer through bubble caps becomes the only effective pathway turning $\mathrm{k}_{\mathrm{L}} \mathrm{a}$ insensitive to bubble length or channel diameter as observed by Berčič and Pintar [18]. Conversely, for short unit cells (bubble + slug lengths $<50 \mathrm{~mm}$ ) and bubble velocities $>0.15 \mathrm{~m} \mathrm{~s}^{-1}$, simulations from van Baten and Krishna [19] showed that scalar transport through the film accounts for $60-80 \%$ of the overall $\mathrm{k}_{\mathrm{L}}$ a values. Experimental results of Vandu et al. [12] also confirmed a dominant film contribution for unit cells lower than $25 \mathrm{~mm}$. This latter scenario becomes especially crucial when a heterogeneous reaction occurs at the catalyst coated wall due the generated concentration gradient, and in this case the proposed chemical engineering models often neglect (with varying degrees of success) the possible interaction between the different transfer pathways [24-26].

One of the rare and complete examples of a development strategy of a MR was illustrated by Haakana et al. [27] who took lactose oxidation as a study case. They used several different mockup experiments to study separately different phenomena, e.g., hydrodynamics, mass transfer and intrinsic kinetics, and ultimately, the different sub-models were combined for a complete mathematical description. Except this relatively detailed study, a methodology for scale-up or design of a MR apparatus accounting for local inter-channel disparities of the hydrodynamics and concentrations stemming from unequal flow distribution in the parallel channels is rarely proposed.

In the present work, a strategy for modelling a MR as a whole is described. The objective is to develop a pre-design tool for industrial-scale reactors applied to highly exothermal reactions. Ascending Taylor flow is assumed in the channels, and a model reaction rate is considered to occur at channel walls. The chosen strategy allows focusing on gas-liquid mass transfer as part and parcel of the entire mass transport mechanisms in the unit cells as a key-point for MR performance. Thus these phenomena are specifically modelled and simulated by means of Computational Fluid Dynamics. For a given set of operating parameters (i.e., fixed gas and liquid flow rates), the overall and local mass transfer rates are quantified and discussed for various values of unit cell length and reaction rate. 


\section{Proposed method for MR modelling}

\subsection{Principles}

In the present work, a pre-design tool for industrial-scale monolith reactors is built thanks to simplifying assumptions and numerical simulations. The studied technology consists in a monolithic metal structure offering thin circular channels dedicated to reaction and a cooling fluid circulating in the hollow structure. The reacting circular channels are $0.2-1 \mathrm{~m}$ long - depending on reaction yield to be achieved-, and have an internal diameter of a few millimetres. The channels can be fed in gas and liquid by means of standard fluid distribution systems (spray nozzle and shower head to name a few) although their inherent imperfections are known to impact the distribution of fluids among the MR channels. The channels are coated with a few micron thin catalytic layers in addition to host a gas-liquid segmented flow (the so-called Taylor flow) resulting in the full problem to be three-dimensional, locally nonstationary and strongly intermingled with coupled multiphysics phenomena (complex hydrodynamics, mass and heat transfer, catalytic reaction) which necessitate descriptions altogether at the film/catalytic layer, channel and reactor scales. The modelling strategy consists in representing each phenomenon with the required level of complexity by progressing step-wise from the local scale to the reactor scale; for that purpose, the CFD software COMSOL Multiphysics ${ }^{\circledR}$ is chosen as it allows to couple the different physics as well as different scales. At each modelling stage, the simulation results will be compared to theoretical results from literature, or to experimental measurements obtained from dedicated setups: jacketed single-channel reactor, cold transparent mock-ups for hydrodynamic regime and mal-distribution purpose, and complete MR.

As a first assumption, a spatially uniform temperature is considered for the monolith framework owing to its high thermal conductivity and to the fast coolant circulation. On the other hand, the effect of uneven fluid distribution will be simply accounted for by combining outflows from channels fed with different gas and liquid flow rates; the way single channels are being fed is based on phase-retention mapping and residence time distribution studies developed in the cold mock-ups.

These two rules are sufficient to use a single-channel approach to model the reactor.

\subsection{Implementation of computational fluid dynamics model}

\subsubsection{General approach}

In this work, an approach inspired from Fukagata et al. [28] and Gupta et al. [29] is chosen for describing Taylor flow in milli- and microchannels using the so-called unit cell (UC, Fig. 1) in which a gas bubble is surrounded by a liquid film and separated by two liquid half-slugs. The UC is represented in a reference frame moving with the bubble. This approach is relevant as long as the considered UC is far enough from the inlet and outlet of the channel. Many computational works dedicated to the modelling of fully-developed Taylor flow in micro- and milli-channels use numerical tracking of the deformation and the motion of gas-liquid interface $[28,30,31]$. Here, because of the low capillary number $\left(\mathrm{O}\left(10^{-3}\right)\right)$, the bubble shape can be considered non-deformable [32]; it is described by means of two hemispherical caps and a cylindrical body of radius $R_{B}$, as depicted in Fig. 1. The channel cross-section being circular, a 2D-axysimmetric representation of the system is used. The film thickness $\delta_{\mathrm{f}}$ beween bubble and wall is estimated from the semi-empirical relation developed by Aussillous and Quéré [33]:

$\frac{\delta_{f}}{d_{c}}=\frac{0.66 C a^{2 / 3}}{1+3.33 C a^{2 / 3}}$

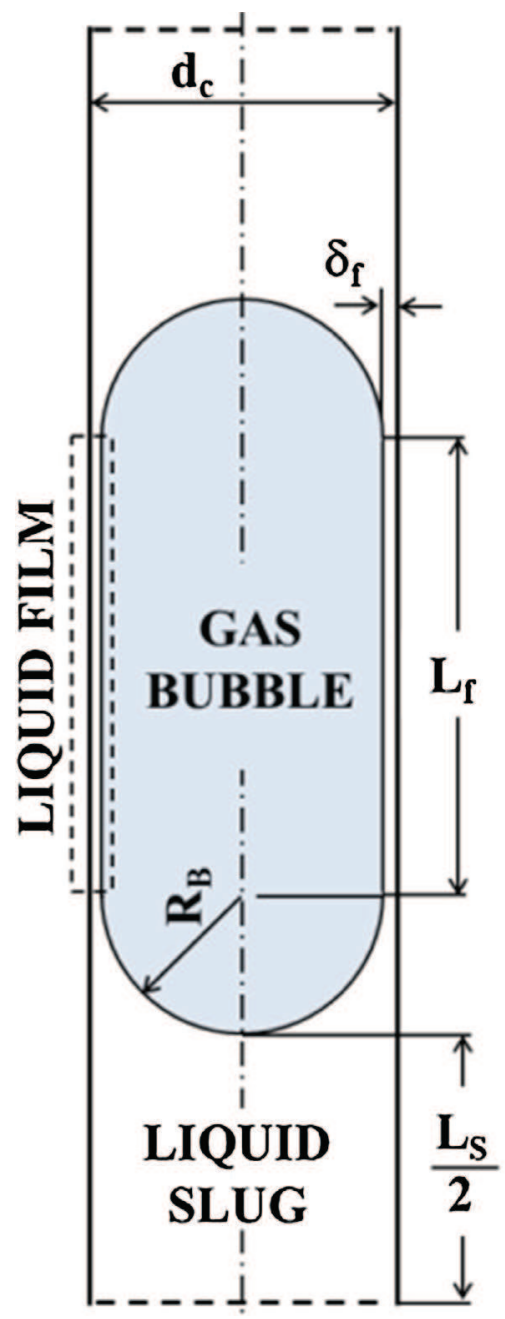

Fig. 1. Unit-cell Taylor flow representation.

In gas-liquid Taylor flow, the pressure gradients in the liquid phase are much greater than those in the gas phase, typically linked to viscosity differences, i.e., $\mu_{L}$ " $\mu_{G}$. Due to the much smaller viscosity in gas phase, viscous effects at the bubble surface are neglected. Furthermore, the bubble being also non-deformable, the influence of gas phase phenomena on liquid phase behavior can be neglected in this problem. Hence, as assumed by other authors [19-21,23], the liquid flow is the only computed phase, and a slip boundary condition (or zero-shear-stress condition) is set at bubble surface. The relevance of this approach will be validated in the following by comparison of hydrodynamic results to literature.

\subsubsection{Mathematical modelling}

The liquid flow is upward, incompressible, and laminar (liquid $\operatorname{Re}<840$ ). Upon enabling mass transfer calculations, the modification of liquid phase properties can safely be neglected (one-way coupling) to consider the liquid hydrodynamics stationary and thus fully obtainable in a decoupled manner. To do so, the CFD software COMSOL Multiphysics ${ }^{\circledR} 5.1$ is used first to solve the following equations:

Continuity equation:

$\nabla \cdot(\rho \boldsymbol{u})=0$

Momentum equation:

$\rho_{L}(\boldsymbol{u} \cdot \nabla) \boldsymbol{u}=-\nabla P+\nabla \cdot\left[\mu_{L}\left(\nabla \boldsymbol{u}+\nabla \boldsymbol{u}^{T}\right)\right]+\rho_{L} \boldsymbol{g}$ 
Once hydrodynamics is solved, the velocity field is used to underlie the calculation of mass exchange between bubble interface and liquid phase. Unlike most of the previous works [19-21,23], a steady-state convection-diffusion equation is solved. The transport of the dissolved gas is thus described by:

$\nabla \cdot\left(-D \nabla c_{L}\right)+\boldsymbol{u} \cdot \nabla c_{L}=0$

Dis-solved gas con-sump-tion is ac-counted for at the UC wall to pre-vent the triv-ial so-lu-tion of com-plete UC sat-u-ra-tion. The boundary conditions of Eqs. (2), (3) and (4) are detailed next.

\subsubsection{Boundary conditions for hydrodynamics modelling}

For hydrodynamics calculations, periodic boundary conditions are set on opposite frontiers of the domain: velocity profiles are forced to be identical on inlet and outlet boundaries, and pressure drop $(\Delta \mathrm{P})$ is imposed. The other boundary conditions are: axial symmetry, moving wall on channel wall, and perfect slip condition on the gas-liquid interface. A pressure constraint point is chosen in the computational domain to establish a reference for pressure field calculation. In this work, as the flow of gas phase is not solved, the computed pressure drop corresponds to single-phase pressure variation of the liquid surrounding an object with wall perfect slip. The pressure drop over the unit cell depends strongly on viscous shear at the wall in the lubrication film and thus on film thickness and on viscosity, and cannot be easily determined; according to literature, the most common value used in similar computational works is zero. However, validity of such an assumption can be challenged by the fact that the energy loss due to the shear stress on the wall is difficult to ignore. To lift such a constraint, numerical evaluation of pressure drop is carried out by means of another simulation strategy, the open unit cell strategy, where a velocity profile is imposed at the inlet boundary, while relative pressure is set to zero at the outlet boundary with condition of normal flow. A Hagen-Poiseuille velocity profile is imposed at inlet boundary which, according to literature, insures very relevant velocity field in film and fully developed slug $[19,34]$. Hence, this open unit cell strategy allows evaluating UC pressure drop, while the periodic strategy captures the exact Taylor flow that develops in the channel at any axial position far from the physical capillary inlet and outlet.

\subsubsection{Mass transfer modelling and processing}

At bubble interface, a Dirichlet boundary condition is used, where dissolved gas concentration is set equal to the thermodynamic saturation $\left(\mathrm{c}^{*}\right)$. The catalytic reaction at the wall acting as a sink induces a local consumption rate of the dissolved gas. A sink flux is set as boundary condition at the wall; the value of this flux is equated with a first order surface reaction rate, the rate constant $\left(\mathrm{K}_{\mathrm{C}}\right)$ of which is $6 \times 10^{-5} \mathrm{~m} \mathrm{~s}^{-1}$. The flux of dissolved gas transferred "interfacially" in the UC was checked to be 3 orders of magnitude lower than its advected flux counterparts entering and leaving the cell. This feature provides prima facie evidence for setting periodic conditions for inlet and outlet boundaries of the unit cell (identical radial profiles in dissolved gas concentration). Thus, the steadystate concentration field is arrived at by viewing mass transfer flux at bubble interface and gas consumption at the wall as strictly equal. It allows evaluation of gas-liquid mass transfer flux for the unit cell: the gas molar flux leaving the bubble $(\mathrm{N})$ is calculated by computing the following surface integral over the gas-liquid interface (axisymmetric mode):

$N=\iint_{\Omega}-D\left(\frac{\partial c}{\partial z} \cdot n_{z}+\frac{\partial c}{\partial r} \cdot n_{r}\right) d S$

where $\Omega$ corresponds to the bubble interface.
A unit cell volumetric mass transfer coefficient can then be defined with respect to the volume averaged concentration of dissolved gas in the unit cell:

$c_{\text {overall }}=\frac{\iiint{ }_{V_{L}} c d V}{\iiint_{V_{L}} d V}$ from:

The volumetric mass transfer coefficient $\mathrm{k}_{\mathrm{L}} \mathrm{a}$ is then calculated

$k_{L} a=\frac{N}{\left(C^{*}-c_{\text {overall }}\right)} * \frac{1}{V_{U C}}$

The transferred gas flux components are likewise dissected for specific zones of the bubble interface: front and back caps, and cylindrical part (lubricating film zone), and their contribution to the overall mass transfer evaluated.

\subsubsection{Studied geometry and operating parameters}

The hydrodynamic characteristics of the Taylor flow in milliand micro-channels, as the ratio of bubble to slug length, the bubble shape and the film thickness $\left(\delta_{\mathrm{f}}\right)$, mainly depend on channel diameter $\left(d_{c}\right)$, fluid properties and superficial velocities. The relevant non-dimensional numbers to describe the problem are the Capillary, Reynolds and Eötvös/Bond numbers: they compare the relative importance between viscous, surface tension, inertia and gravitational effects $[29,32,35]$. The present work focuses on the description of Taylor flow in the reacting circular channels of a monolith, and the geometry details are inspired from a study case developed by van Baten and Krishna [19] which characteristic parameters are shown in Table 1 (reference case of this work).

The developed Taylor flow depends on the set of gas and liquid flow rates whereby various unit cell lengths, and thus various bubble frequencies, are to occur. The unit cell length ( $\mathrm{L}_{\mathrm{UC}}$ ) cannot be $a$ priori determined; in experiments this length is controlled by the fluid properties and by the technology of the feeding system (T or Y-junction, for instance). To check the influence of unit cell length (or bubble frequency) onto mass transfer efficiency, several unit cell lengths are tested (Table 1).

\subsubsection{Mesh features, numerical parameters and sensitivity study}

CFD modelling of Taylor flow needs special care regarding mesh resolution especially nearby the interfaces where steep velocity and concentration gradients emerge, in particular in the very thin lubrication liquid film. As documented by several authors [30,36], poor mesh resolution prevents capture of the exact details of the flow field around the bubble. Thus, Gupta et al. [30] recommended a minimum of five mesh elements across the liquid film. In the present work, a user-controlled mesh was used (See additional figure in Appendix A): a free triangular mesh is built on the domain, and optimized by adjusting element size and growth rate near bubble surface and channel wall. A boundary layer mesh (quadrilateral elements) was also created close to these boundaries.

To make sure that the implemented mesh is precise enough, a mesh sensitivity study was performed by varying the number and size of elements and by checking the variations of the calculated pressure drop in the unit cell (UC). For the UC of reference (same geometry as van Baten \& Krishna's case), the number of elements was increased from 33,347 to 226,789 (Table 2). As a compromise between computational time and results accuracy, a grid with 77,318 cells where the smallest element size is $0.8 \mu \mathrm{m}$, was chosen. For comparison, van Baten \& Krishna used 72,890 elements and $1 \mu \mathrm{m}$ smallest cell size. For each UC length, the same strategy was repeated to obtain relevant a mesh.

Furthermore, to achieve results with higher accuracy, a P2-P1 mixed-order interpolation scheme has been then used with piecewise quadratic approximation of velocity components and 
Summary of input data for the numerical study.

\begin{tabular}{|c|c|c|c|c|c|c|c|c|c|c|c|c|}
\hline \multirow[b]{2}{*}{ Case } & \multicolumn{9}{|c|}{ Input parameters } & \multicolumn{3}{|c|}{ Computed parameters } \\
\hline & $\mathrm{d}_{\mathrm{c}}(\mathrm{mm})$ & $\mathrm{L}_{\mathrm{UC}}(\mathrm{mm})$ & $\varepsilon_{\mathrm{G}}(-)$ & $\mathrm{L}_{\mathrm{f}}(\mathrm{mm})$ & $\delta_{\mathrm{f}}(\mu \mathrm{m})$ & $\mathrm{U}_{\mathrm{B}}\left(\mathrm{m} \mathrm{s}^{-1}\right)$ & $\mathrm{K}_{\mathrm{C}}\left(\mathrm{m} \mathrm{s}^{-1}\right)$ & $\mathrm{c}^{*}\left(\mathrm{~mol} \mathrm{~m}^{-3}\right)$ & $\mathrm{D}\left(\mathrm{m}^{2} \mathrm{~s}^{-1}\right)$ & $\mathrm{U}_{\mathrm{TP}}\left(\mathrm{m} \mathrm{s}^{-1}\right)$ & $\mathrm{Q}_{\mathrm{L}}$ & $\left(\mathrm{ml} \mathrm{s}^{-1}\right)$ \\
\hline 1: ref & 3 & 40.0 & 0.17 & 5.320 & 48 & 0.3 & $6 \times 10^{-5}$ & 1.3 & $1 \times 10^{-9}$ & 0.28 & & 1.62 \\
\hline 2 & 3 & 20.0 & 0.17 & 1.692 & 48 & 0.3 & $6 \times 10^{-5}$ & 1.3 & $1 \times 10^{-9}$ & 0.28 & & 1.62 \\
\hline 3 & 3 & 13.3 & 0.17 & 0.483 & 48 & 0.3 & $6 \times 10^{-5}$ & 1.3 & $1 \times 10^{-9}$ & 0.28 & & 1.62 \\
\hline
\end{tabular}

Table 2

Mesh details for the sensitivity analysis for the case $\mathrm{L}_{\mathrm{UC}}=0.04 \mathrm{~m}$.

\begin{tabular}{|c|c|c|c|c|c|}
\hline & Total mesh elements & Smallest element size $(\mu \mathrm{m})$ & Biggest element size $(\mu \mathrm{m})$ & Elements in liquid film & $\Delta \mathrm{P}_{\text {Openuc }}(\mathrm{Pa})$ \\
\hline 1 & 33,347 & 3.0 & 155 & 17 & 283 \\
\hline 2 & 77,318 & 0.8 & 155 & 19 & 324 \\
\hline 3 & 151,616 & 0.2 & 87 & 22 & 331 \\
\hline 4 & 226,798 & 0.2 & 67 & 22 & 325 \\
\hline
\end{tabular}

(a)

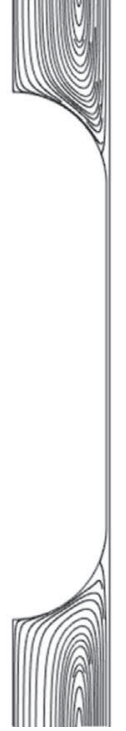

(b)

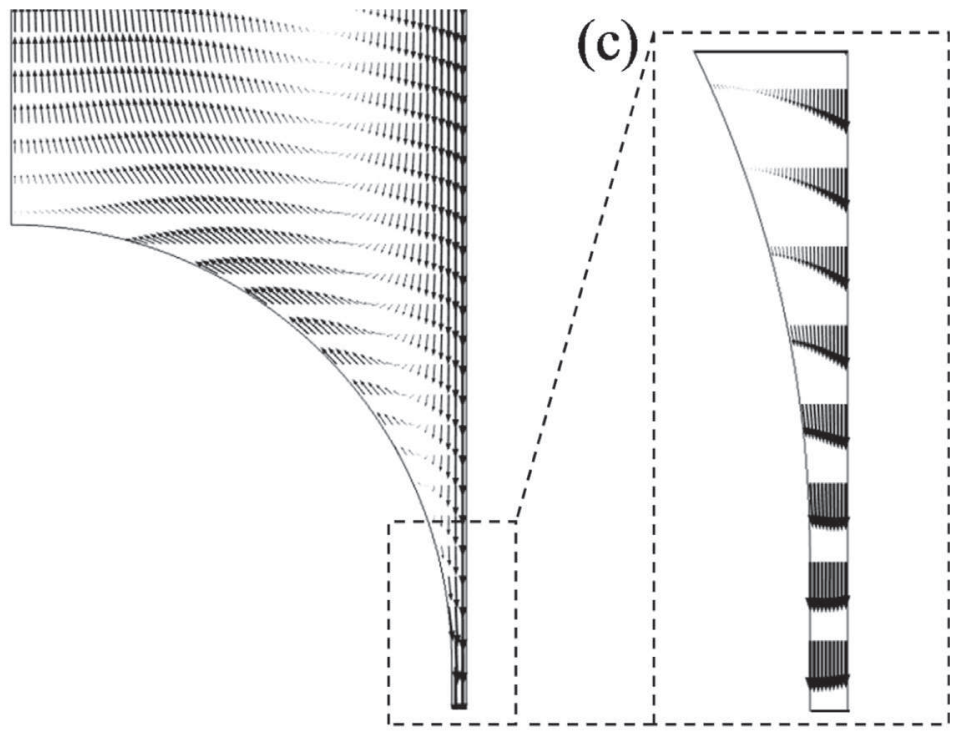

Fig. 2. Streamlines (a) and liquid velocity vectors (b) obtained from CFD simulation for the reference case (Case 1, see Table 1). Zoomed area (c) corresponds to the entrance of liquid film.

piecewise linear approximation of pressure. P3 finite elements are applied for concentration field. In these conditions, less than $2 \%$ difference has been found between Mesh 2 and 4 for both pressure gradient and volumetric mass transfer coefficient.

\section{Results and discussion}

\subsection{Velocity field}

We recall that Mesh 2 (see Table 2) is used. Boundary conditions of perfect slip and no slip are set on bubble interface and channel wall, respectively. The UC pressure drop is evaluated in advance by means of an open unit cell calculation.

\subsubsection{Velocity contours and velocity profiles in slug and in film}

For the reference case (case 1, Table 1), Fig. 2 shows the velocity field obtained in a frame moving with the bubble where the recirculation streamlines take indeed place in the slug (Fig. 2a,b). In addition, Fig. $2 c$ shows that, in the lubrication film, the flow develops rapidly showcasing translational invariance of the velocity profile from $\mathrm{z}=0.1 \mathrm{~mm}$ from film entrance; in the film the liquid appears to move opposite to the direction of bubble motion.

Slug vortices are induced by viscous effects initiated in the vicinity of wall and can be observed in slugs in Taylor flows for $\mathrm{Ca}<0.5$
[37]. This behavior was first reported by Taylor in 1961 [38] and has been confirmed by numerous experimental and numerical studies $[39,40]$. The slug recirculatory motion is at the origin of the notorious intense mixing, heat and mass transfer observed in Taylor flows. Transposing the radial velocity profiles in the laboratory frame (stationary wall, rising bubble) provides post-facto confirmation that a Hagen-Poiseuille flow is retrieved in the major part of the slug (Fig. 3a). This behavior is expected when considering that the liquid slug is sufficiently long to allow a fully developed flow to be attained away from bubble nose and tail [39]. In the stationary frame, the mean velocity of liquid flow (i.e., velocity averaged over channel cross section) is equal to $U_{T P}$, where $U_{T P}$ is defined as the sum of superficial velocities of gas and liquid. However, as classically observed in Taylor flows [41], the bubble moves slightly faster than $U_{T P}$ and, to satisfy mass conservation, liquid moves slower than the bubble in the film region, and in some cases it moves in the opposite direction. In the present described situation, "downward" motion of liquid occurs in the film; as a consequence, in the frame of reference moving with the bubble, liquid is observed to move downward and slightly faster than the wall.

\subsubsection{Influence of pressure difference over unit cell}

The value to be taken for unit cell pressure drop in liquid phase $\Delta \mathrm{P}$ is hardly discussed in literature describing computational stud- 


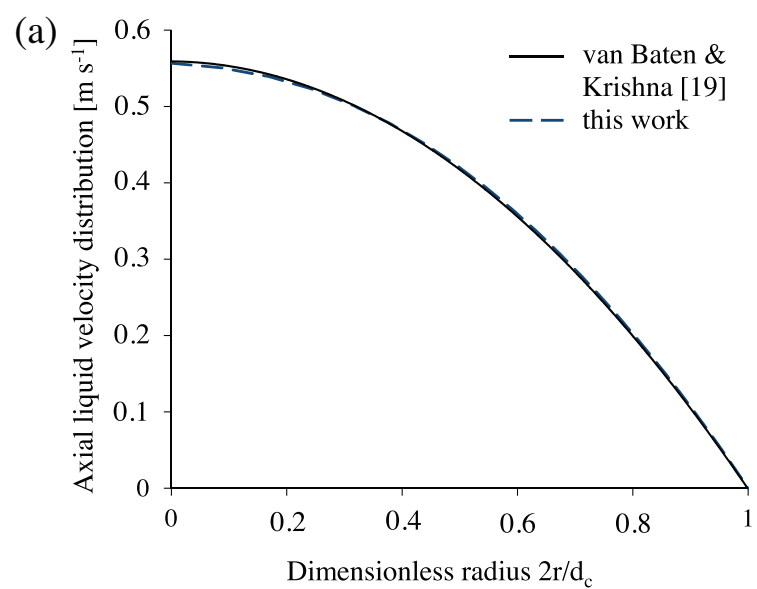

(b) Dimensionless distance along the liquid film $\left(\mathrm{r}-\mathrm{R}_{\mathrm{B}}\right) / \delta_{\mathrm{f}}$

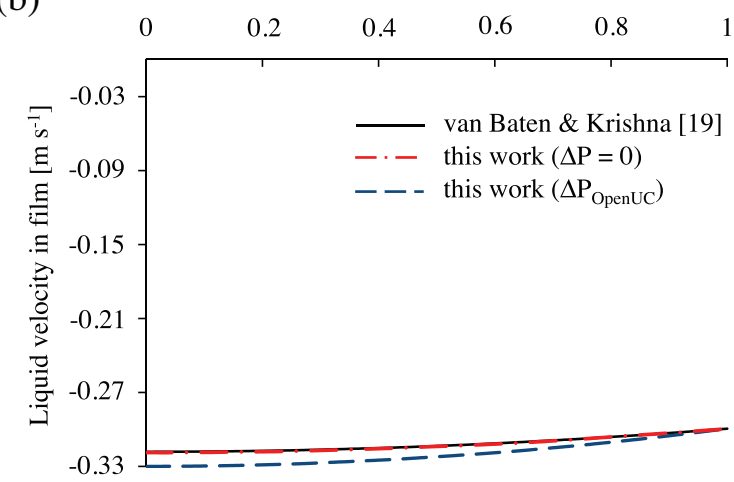

Fig. 3. Comparison of radial distribution of liquid velocity in slug (far from bubble caps) in laboratory frame (a), and liquid film velocity profile in bubble reference frame (b). Simulation of reference case (case 1, Table 1).

ies based on the periodic unit cell approach. In the work of Shao et al. [20] for instance, gravitational forces are neglected because the channel is horizontal, and pressure drop due to viscous shear is taken to 0 over the unit cell (" $\mathrm{P}_{\mathrm{in}}=\mathrm{P}_{\text {out }}$ "); in that of van Baten and Krishna [19] (upflow configuration) only hydrostatic pressure appears to have been accounted for. To check the relevance of this choice, the $\Delta \mathrm{P}$ value imposed accross computational domain is varied in the present work; the velocity profile at outlet of the film zone is scrutinized for both scenarii. As observed on Fig. 3b, the velocity profile obtained when pressure drop is forced to 0 and gravitational force neglected in Eq. (3) is in excellent agreement with the profile found by van Baten and Krishna; in particular, a velocity magnitude of $-0.32 \mathrm{~m} \mathrm{~s}^{-1}$ is observed at bubble interface. When pressure drop over the unit cell is forced to the value previously computed from the open Unit Cell approach, liquid flows slightly faster in the film and the interfacial velocity reaches $-0.33 \mathrm{~m} \mathrm{~s}^{-1}$. This tiny gap represents a low relative difference of $3 \%$ for maximum velocity in film region whereas, in the middle of the slug, where Poiseuille profile is established, the two assumptions lead to very similar velocity values on channel axis too ( $0.84 \%$ of relative difference).

These results explain and approve practices found in previous CFD studies: as far as hydrodynamics are concerned, pressure drop over unit cell can be neglected.

\subsubsection{Influence of boundary condition used at bubble interface}

To check further the reliability of the present calculations, the velocity profile in the developed zone of the lubrication film is compared to the analytical model proposed by Abiev [41]. This author derived an exact lubrication solution of gas and liquid flows in the channel cross-section where the film is fully developed. Con-

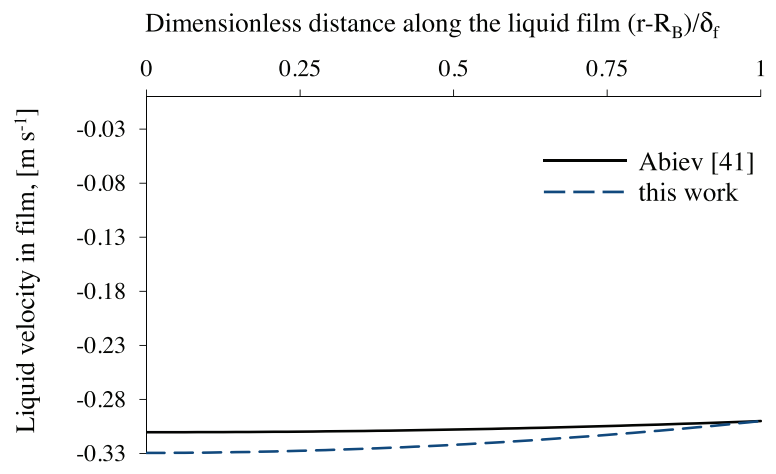

Fig. 4. Velocity profiles in liquid film for different boundary conditions at bubble surface (case 1 , see Table 1 ).

tinuity and momentum equations are analytically solved for both phases. At gas-liquid interface, the continuity of the distribution of the velocity and shear stress is set as boundary condition:

$$
\begin{aligned}
& \left.u_{z G}\right|_{r=R_{B}}=\left.u_{z L}\right|_{r=R_{B}} \\
& \left.\mu_{G} \frac{\partial u_{z G}}{\partial r}\right|_{r=R_{B}}=\left.\mu_{L} \frac{\partial u_{z L}}{\partial r}\right|_{r=R_{B}}
\end{aligned}
$$

In the lubrication solution, the pressure drop is an output of the model. The velocity profile obtained for liquid phase with Abiev's model is plotted in Fig. 4 along with the one obtained with $\mathrm{COMSOL}^{\circledR}$ using perfect slip condition at bubble surface and a value of pressure drop issued from open unit cell calculation. As can be seen, the perfect slip condition leads to results close to Abiev's model; in particular, both maximum axial velocities in the film (at bubble surface) differ of $6 \%$ only. Therefore the perfect slip condition is relevant to model liquid flow in the unit cell.

The influence on mass transport of the slight difference in liquid flow rate in the film has still to be further investigated to highlight the impact of the two boundary conditions discussed above.

\subsection{Concentration field}

Contour plots of simulated concentration (Fig. 5a) show that the liquid phase content in the slug is almost uniform in dissolved gas, showing an average concentration of $85 \%$ of $c^{*}$. Some thin zones are close to saturation (Fig. 5b): a diffusion layer near bubble interface, and a band along channel axis, where dissolved gas is advected by liquid flow recirculation. Zooming near the wall (Fig. 5c) instructs on the fact that a concentration gradient takes place crosswisse through the entire film thickness by virtue of the wall reaction, and that the finite reaction characteristic time allows at the wall a low (but non-zero) dissolved gas concentration (20\% of $\mathrm{c}^{*}$ ).

\subsection{Mass transfer characteristics}

The mass transfer behavior will be described in detail for the reference case (case 1 , Table 1 ), and for additional reparameterized cases where the reaction rate constant and bubble frequency are varied. The first objective out of this sensitivity exercise is to understand which parts of the bubble interface are the main contributors to the unit cell overall mass transfer. The second is to highlight any influence of bubble frequency on UC mass transfer efficiency, in which instance this parameter should be taken into account in monolith reactor design and scale-up. This point introduces a peculiar complexity into the problem, as it is difficult, especially in industrial operations, to either predict or control how gas and liquid split and re-agregate into bubbles and slugs at channel inlet. The dependency of bubble and slug lengths on operating parameters has been extensively studied. However, despite a 


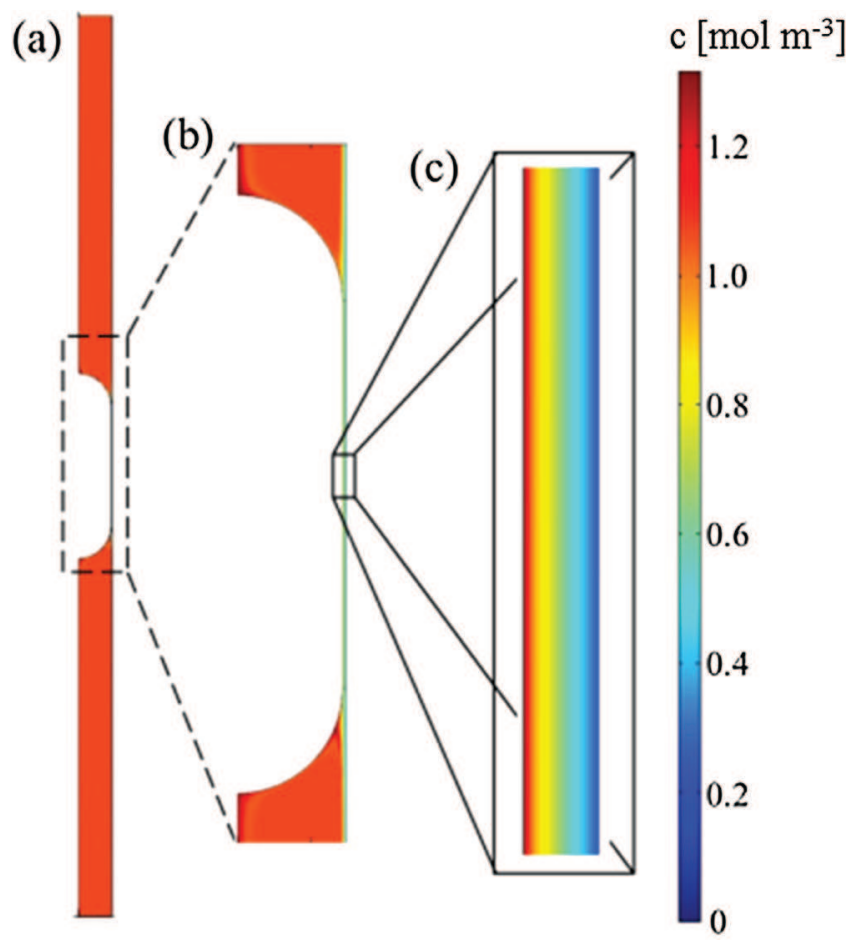

Fig. 5. Concentration field over the entire UC domain (a) with zoomed area near the bubble (b), and in the liquid film (c). Simulation for case 1 (Table 1).

number of empirical correlations thus far proposed, yet the heterogeneous outcomes out of them still suggest that this aspect requires more mature understanding to be achieved in the future [42].

\subsubsection{Reference case}

As explained earlier, the volumetric mass transfer coefficient, $\mathrm{k}_{\mathrm{L}} \mathrm{a}$, is derived from the field of dissolved gas concentration. An overall value of $0.08 \mathrm{~m}^{3} \mathrm{~L} \mathrm{~m}^{-3} \mathrm{UC} \mathrm{S}^{-1}\left(0.09 \mathrm{~s}^{-1}\right.$ related to the liquid volume) is obtained for the unit cell for a total bubble surface of $7.50 \times 10^{-5} \mathrm{~m}^{2}$ tantamount to an interfacial area of $265.36 \mathrm{~m}^{2}$ per $\mathrm{m}^{3}$ of unit cell.

It is worth mentioning that stationary simulations of a single periodic unit cell do not take into account the entrance section of channel, where liquid phase is often almost free from dissolved gas leading to high gas-liquid transfer rate. As a consequence, the present approach probably slightly under-estimates the $\mathrm{k}_{\mathrm{L}}$ a values, in regard with the corresponding experimental situations. However, the tube length allowing the development of a stable concentration field in the unit cell is probably very short: as described by authors performing dynamic simulation of mass tranfer in a unit cell with homogeneous reaction [20], this distance corresponds roughly to the time needed for the liquid in the slug to enrich in dissolved gas in the vicinity of bubble caps, that is to describe a complete circulation cycle within the slug. For the present case of simulation, it represents less than two times the unit cell length.

With respect to the validation of the chosen boundary conditions and to the slight difference in liquid flow rate they induce for the film region, it is important to note that the mean slug concentration and $\mathrm{k}_{\mathrm{L}}$ a values differ by $0.6 \%$ and $1.1 \%$ only, respectively, when pressure drop is taken into account or not. As a consequence, it can be stated that a small difference in the transport of dissolved gas from film to back half-slug has no significant influence of mass transfer characteristics. This definitively validates the conventional choices found in literature for unit cell pressure drop and interface boundary conditions.
The calculated $\mathrm{k}_{\mathrm{L}} \mathrm{a}$ values are compared to those derived from several literature correlations, given in Table 3. These relations were obtained for different configurations (regarding film saturation level) and either from experimental or numerical results. Berčič \& Pintar's correlation (Eq. (A)) was built based on experimental results of methane absorption in water obtained in capillaries of $1.5,2.5$ and $3.1 \mathrm{~mm}$ diameter. The authors reported that major part of mass transfer occured through the bubble caps, probably as liquid film was quickly saturated in their conditions [12]. Therefore, $\mathrm{k}_{\mathrm{L}} \mathrm{a}$ was found to mostly depend upon liquid slug length and velocity, while gas bubble length and channel diameter had a negligible effect. Van Baten \& Krishna's correlation (Eqs. (B) and (C)) was obtained from CFD simulations. It splits $\mathrm{k}_{\mathrm{L}} \mathrm{a}$ into two principal contributions: one from the bubble caps and the other from the film. The first one is based on Higbie's penetration model and the second one on falling film model. Eq. (B) uses the exact dimensions of bubble, film and slug, unlike Eq. (C) where these dimensions are estimated from knowledge of the operating parameters. Eq. (D) proposed by Vandu et al. [12] considers the film contribution only, based on van Baten and Krishna's work: the constant factor was verified to be 4.5 as best fitting their experimental data obtained from experiments of air absorption in water in 1-3 mm capillaries with circular and square cross-sections. This correlation should then be valid for Taylor flows in which film contribution is dominant. Eq. (E) from Yue et al. [15] was derived for narrow channels $(<1 \mathrm{~mm})$ in addition to high gas and liquid superficial velocities $\left(1 \mathrm{~m} \mathrm{~s}^{-1}<\mathrm{U}_{\mathrm{TP}}<12 \mathrm{~m} \mathrm{~s}^{-1}\right)$. Shao et al. [20] tuned the multiplicative constant in Eq. (D) to match CFD results for the case of $\mathrm{CO}_{2}$ absorption into an aqueous solution of $\mathrm{NaOH}$.

Comparison between present $\mathrm{k}_{\mathrm{L}}$ a values and those predicted by van Baten and Krishna's correlation (Eq. (B) in Table 3) shows a difference of $5.3 \%$. Note that the present simulations correspond to the conditions used by van Baten and Krishna, i.e., short contact time of the liquid film $\left(t_{\text {film }}<0.1 \delta_{\mathrm{f}}^{2} \mathrm{D}^{-1}\right)$. Eq. (C) with estimated parameters leads to less accurate results than Eq. (B), as can be seen on Fig. 6.

Correlations from Vandu et al. [12] (Eq. (D)) and Shao et al. [20] (Eq. (F)) in which film contribution is preponderant underpredict the $\mathrm{k}_{\mathrm{L}}$ a value. In contrast, Berčič and Pintar correlation [18] (Eq. (A)) was established for long bubbles with almost saturated films and does not reflect the present simulated conditions; it leads to an overprediction of mass transfer coefficient. Finally, Eq. (E) by Yue et al. [15] underestimates our current results, probably because it was derived for channels much narrower than in this study in addition to much higher gas and liquid superficial velocities.

The good agreement obtained with Eq. (B) proves the relevance of the simplified approach proposed in the present work to describe mass transfer in thin channels (stationnary mode, gas phase not modelled).

Table 4 summarizes the contributions of different parts of bubble surface to mass transfer as obtained in our simulation. As long as experimental studies are unable to achieve such contributional dissections, our approach can prove very useful in gaining insights in this complext subject. Table 4 shows that film surface represents $64 \%$ of total bubble surface and contributes to $64 \%$ of overall transferred molar flux.

Notwithstanding, our simulation result is in agreement with general observations that lubrication film contribution is the major one in the case of wall reaction [12]. Each bubble cap represents $18 \%$ of total bubble surface only, but front cap contributes 4 times more than back cap to mass transfer, as the corresponding relative mass transfer fluxes are $29 \%$ and $7 \%$, respectively. The quite limited contribution of bubble back cap can be explained by the moderate liquid velocities (Fig. 7) observed in the vicinity of bubble back cap as compared to front cap, leading to moderate drainage of dissolved gas in this region. 
Table 3

Correlations from literature used for comparison with $\mathrm{k}_{\mathrm{L}}$ a values.

\begin{tabular}{|c|c|c|}
\hline Authors & Correlation & Equation \\
\hline Berčič \& Pintar [18] & $k_{L} a=0.111 \frac{U_{T P}^{1.19}}{\left[\left(1-\varepsilon_{G}\right) L_{U C}\right]^{0.57}}$ & (A) \\
\hline van Baten \& Krishna [19] & $k_{L} a=\frac{2 \sqrt{2}}{\pi} \sqrt{\frac{D U_{B}}{d_{c}}} \frac{4 d_{B}^{2}}{L_{U C} d_{c}^{2}}+\frac{2}{\sqrt{\pi}} \sqrt{\frac{D U_{B}}{L_{f}}} \frac{4 d_{B} L_{f}}{d_{c}^{2} L_{U C}}$ & (B) \\
\hline van Baten \& Krishna [19] & $k_{L} a=\frac{2 \sqrt{2}}{\pi} \sqrt{\frac{D U_{B}}{d_{C}}} \frac{4}{L_{U C}}+\frac{2}{\sqrt{\pi}} \sqrt{\frac{D U_{B}}{\varepsilon_{G} L_{U C}}} \frac{4 \varepsilon_{G}}{d_{C}}$ & (C) \\
\hline Vandu et al. [12] & $k_{L} a=4.5 \sqrt{\frac{D u_{G S}}{L_{L S}}} \frac{1}{d_{c}}$ & (D) \\
\hline Yue et al. [15] & $S h_{L} \cdot a \cdot d_{c}=0.084 R e_{G}^{0.213} R e_{L}^{0.912} S c_{L}^{0.5}$ & (E) \\
\hline Shao et al. [20] & $k_{L} a=3 \sqrt{\frac{D u_{G S}}{L_{U C}}} \frac{1}{d_{c}}$ & $(\mathrm{~F})$ \\
\hline
\end{tabular}

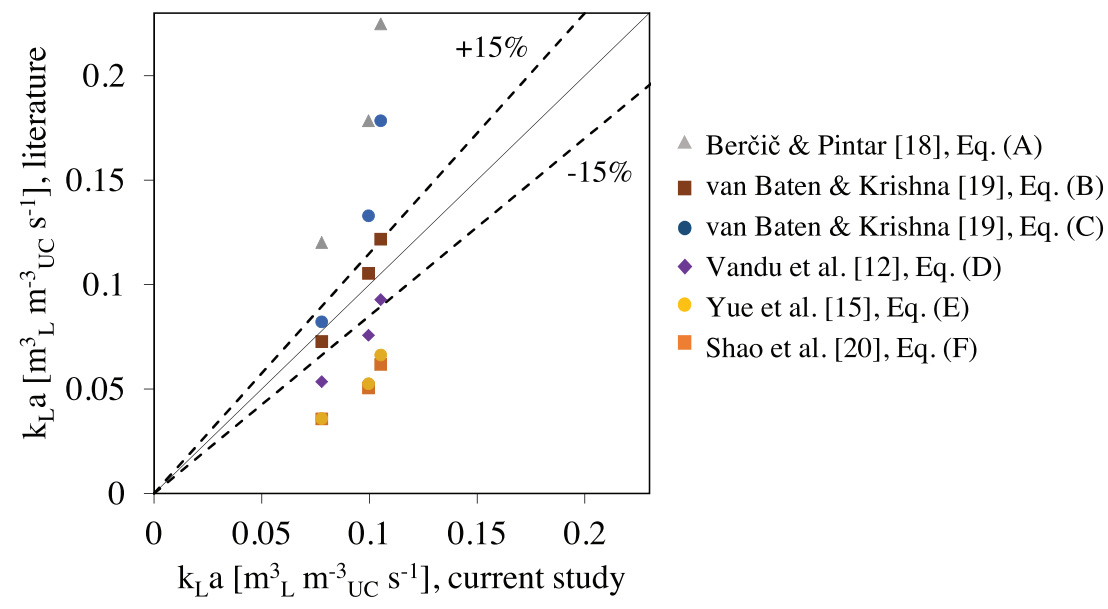

Fig. 6. Comparison of mass transfer coefficients computed in this work against those predicted from several literature correlations.

Table 4

Comparison of surface, molar flux and density flux for different zones of the UC (case of reference).

\begin{tabular}{|c|c|c|c|c|c|}
\hline & Bubble nose & Film & Bubble tail & Unit Cell & Units \\
\hline Surface & $\begin{array}{l}1.32 \times 10^{-5} \\
18 \%\end{array}$ & $\begin{array}{l}4.85 \times 10^{-5} \\
64 \%\end{array}$ & $\begin{array}{l}1.32 \times 10^{-5} \\
18 \%\end{array}$ & $7.50 \times 10^{-5}$ & {$\left[\mathrm{~m}^{2}\right]$} \\
\hline Molar flux & $\begin{array}{l}1.70 \times 10^{-9} \\
29 \%\end{array}$ & $\begin{array}{l}3.71 \times 10^{-9} \\
64 \%\end{array}$ & $\begin{array}{l}4.07 \times 10^{-10} \\
7 \%\end{array}$ & $5.82 \times 10^{-9}$ & {$\left[\mathrm{~mol} \mathrm{~s}^{-1}\right]$} \\
\hline $\mathrm{k}_{\mathrm{L}} \mathrm{a}$ & 0.02 & 0.01 & 0.01 & 0.08 & {$\left[\mathrm{~m}^{3}{ }_{\mathrm{L}} \mathrm{m}^{-3} \mathrm{UC}^{-1}\right]$} \\
\hline
\end{tabular}

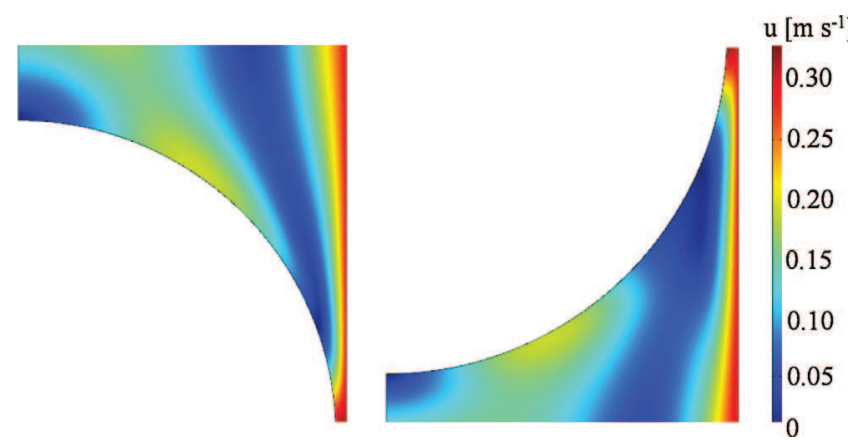

Fig. 7. Velocity field on bubble front and back caps for case 1 (Table 1).

Furthermore, our steady-state approach offers the possibility of calculation of "local" volumetric mass transfer coefficients, related to gas-liquid interfacial area calculated for different parts of the bubble, and to local average concentration in liquid phase. It has to be borne in mind that, for the film area, the driving force used in $\mathrm{k}_{\mathrm{L}}$ a calculation is taken as $\left(\mathrm{c}^{*}-\mathrm{c}_{\text {wall }}\right)$. The values gathered in Table 4 show for the present case with wall reaction that $\mathrm{k}_{\mathrm{L}}$ a value, unlike mass transfer flux, is more important for bubble front cap with regard to film and back cap values. This observation raises then the following question: is film contribution to mass transfer flux still dominant when film surface is significantly reduced? This point is checked in the next section.

\subsubsection{Influence of bubble frequency}

With respect to the reference case, additional situations are simulated, where gas and liquid flow rates are kept constant, as well as bubble velocity and gas holdup in unit cell, and where bubble frequency is the only varied parameter. $\mathrm{L}_{\mathrm{UC}}$ (reference value is $40 \mathrm{~mm}$, corresponding to 25 bubbles per meter on channel) is divided by factors 2 and 3 (hereinafter referred to as "case 2" and "case 3", respectively), leading to smaller bubbles (Fig. 8): bubble surface reaches $56 \%$ and $41 \%$ of total reference bubble surface, respectively. On the other hand, unit cell length decreases with increasing bubble frequency in a less extent than bubble surface, leading to higher gas-liquid area per cubic meter of channel. Table 5 summarizes the considered cases and the main results.

As observed, the overall $\mathrm{k}_{\mathrm{L}}$ a value is improved by $35 \%$ for a threefold increase of bubble frequency (from case of reference to case $3)$. This $k_{L}$ a enhancement cannot be fully attributed to the increase of interfacial area, which is only of $21 \%$. A probable explanation is that shorter slugs lead to intensified liquid recirculation and thus to more efficient transport processes.

Back bubble cap remains poorly contributing, with only $19 \%$ of the overall transferred gas rate in case 3. Bubble surface in the film area decreases with bubble frequency (accounting for only $14 \%$ only 


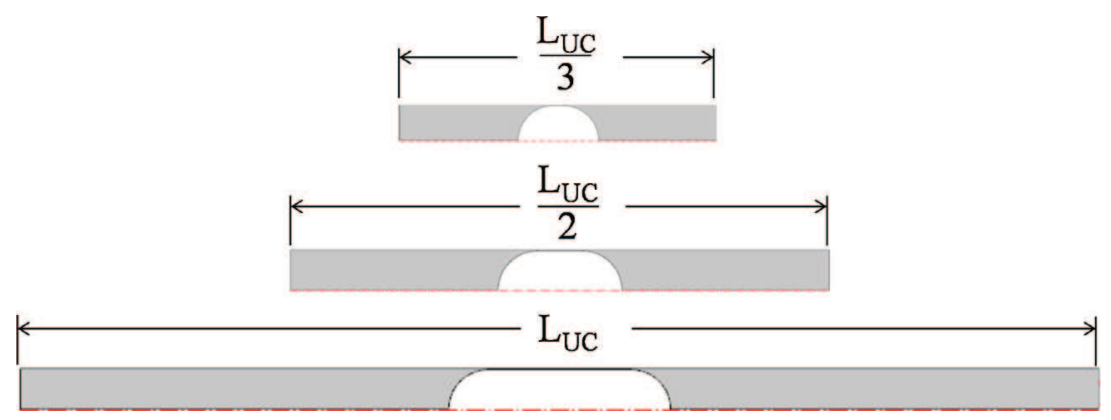

Fig. 8. Unit Cell characteristics for different studied cases.

Table 5

Contributions to mass transfer of the different zones of the bubble for three $\mathrm{L}_{\mathrm{UC}}$ tested.

\begin{tabular}{|c|c|c|c|c|c|c|}
\hline & & Bubble nose & Film & Bubble tail & Unit Cell & Units \\
\hline Reference & Surface & $1.32 \times 10^{-5}$ & $4.85 \times 10^{-5}$ & $1.32 \times 10^{-5}$ & $7.50 \times 10^{-5}$ & {$\left[\mathrm{~m}^{2}\right]$} \\
\hline \multirow[t]{4}{*}{ case } & & $18 \%$ & $64 \%$ & $18 \%$ & & \\
\hline & Molar flux & $1.70 \times 10^{-9}$ & $3.71 \times 10^{-9}$ & $4.07 \times 10^{-10}$ & $5.82 \times 10^{-9}$ & {$\left[\mathrm{~mol} \mathrm{~s}^{-1}\right]$} \\
\hline & & $29 \%$ & $64 \%$ & $7 \%$ & & \\
\hline & $\mathrm{k}_{\mathrm{L}} \mathrm{a}$ & 0.02 & 0.01 & 0.01 & 0.08 & {$\left[\mathrm{~m}^{3}{ }_{\mathrm{L}} \mathrm{m}^{-3} \mathrm{uc} \mathrm{s}^{-1}\right]$} \\
\hline \multirow[t]{5}{*}{ Case 2} & Surface & $1.32 \times 10^{-5}$ & $1.54 \times 10^{-5}$ & $1.32 \times 10^{-5}$ & $4.19 \times 10^{-5}$ & {$\left[\mathrm{~m}^{2}\right]$} \\
\hline & & $32 \%$ & $36 \%$ & $32 \%$ & & \\
\hline & Molar flux & $1.31 \times 10^{-9}$ & $1.35 \times 10^{-9}$ & $3.47 \times 10^{-10}$ & $3.01 \times 10^{-9}$ & {$\left[\mathrm{~mol} \mathrm{~s}^{-1}\right]$} \\
\hline & & $44 \%$ & $45 \%$ & $11 \%$ & & \\
\hline & $\mathrm{k}_{\mathrm{L}} \mathrm{a}$ & 0.04 & 0.01 & 0.01 & 0.10 & {$\left[\mathrm{~m}^{3}{ }_{\mathrm{L}} \mathrm{m}^{-3} \mathrm{UC} \mathrm{S}^{-1}\right]$} \\
\hline \multirow[t]{5}{*}{ Case 3} & Surface & $1.32 \times 10^{-5}$ & $4.40 \times 10^{-6}$ & $1.32 \times 10^{-5}$ & $3.09 \times 10^{-5}$ & {$\left[\mathrm{~m}^{2}\right]$} \\
\hline & & $43 \%$ & $14 \%$ & $43 \%$ & & \\
\hline & Molar flux & $1.58 \times 10^{-9}$ & $5.81 \times 10^{-10}$ & $5.14 \times 10^{-10}$ & $2.68 \times 10^{-9}$ & {$\left[\mathrm{~mol} \mathrm{~s}^{-1}\right]$} \\
\hline & & $59 \%$ & $22 \%$ & $19 \%$ & & \\
\hline & $\mathrm{k}_{\mathrm{L}} \mathrm{a}$ & 0.06 & 0.01 & 0.02 & 0.11 & {$\left[\mathrm{~m}^{3} \mathrm{~L} \mathrm{~m}^{-3} \mathrm{UC} \mathrm{S}^{-1}\right]$} \\
\hline
\end{tabular}

of total bubble surface for the highest tested bubble frequency), and so does its contribution to overall unit cell mass transfer rate, reaching $22 \%$ only for case 3 ; film contribution dominance stops in benefit to bubble front cap contribution ( $59 \%$ of total transferred mass, in case 3 ). To offset this phenomenon, film contribution could be enhanced via a steeper concentration gradient between bubble and wall, i.e., by thinning the film or in other words by slowing the flow. However, faster flow would enhance circulation within slugs, as recommended in the literature [42]. In situations where film contribution to mass transfer is dominant, low superficial velocities should still be prefered, keeping in mind that total superficial fluid velocity directly impacts the overall residence time and channel reaction yield.

Considering the steep concentration gradients near the wall when a catalytic reaction is present, the influence of reaction rate on film and cap contributions may be of primary importance.

\subsubsection{Influence of reaction rate at the wall}

From case of reference $\left(\mathrm{L}_{\mathrm{UC}}=0.040 \mathrm{~mm}\right.$ and $\left.\mathrm{K}_{\mathrm{C}}=6 \times 10^{-5} \mathrm{~m} \mathrm{~s}^{-1}\right)$, three new cases are described, where reaction rate coefficient $\mathrm{K}_{\mathrm{C}}$ is quenched by a factor of 50 (case ( $\left.1^{\prime}\right)$ ), or inflated by a factor of 5 (case $\left(2^{\prime}\right)$ ), or brought to infinity, i.e., $c_{\text {wall }}=0\left(\right.$ case $\left.\left(3^{\prime}\right)\right)$. For the four cases examined here, bubble surface, unit cell dimensions, and operating parameters (fluid flow rates) are identical. The results in volume average concentration in slug, wall concentration, mass transfer flux, and local or global $\mathrm{k}_{\mathrm{L}}$ a values, are summarized in Table 6 . As expected, the average slug concentration ( $\mathrm{c}_{\mathrm{s} \text {, mean }}$ ) and wall concentration decrease upon igniting further the reaction rate. It can be observed that, in all cases, the mean concentration in dissolved gas is the same for the front and the back half-slugs. For slow reaction rate (case $\left(1^{\prime}\right)$ ), the slug average concentration equals $98 \%$ of saturation concentration, whereas it reaches $74.8 \%$ for infinite reaction rate $\left(c_{\text {wall }}=0\right)$. Similarly, the overall molar transferred flux in the unit cell (i.e., molar flux due to reaction rate at wall) increases sharply with increasing rate constant. Interestingly, these increases are not proportional since $\mathrm{c}_{\text {wall }}$ also simultaneously decreases for a soaring $\mathrm{K}_{\mathrm{C}}$ value.

Irrespective of the studied cases, contributions of film and caps to mass transfer flux are strictly the same. This observation proves that, for short non-saturated films, mass flux exchanged between bubble and wall may depend on operating parameters and on bubble and slug relative dimensions, but not on reaction rate at the wall.

\section{Conclusions and perspectives}

This mass transfer study was part of a wider modelling strategy which aims at modelling a monolith reactor as a whole by accounting only for the required level of complexity for the description of the phenomena occurring at the film, channel and reactor scales. Comparison with results of a multiphase flow model proved that at low capillary numbers, the hydrodynamics of Taylor flow can be adequately approximated by calculations on liquid phase only, neglecting unit cell pressure drop and using slip conditions at the bubble interface.

Gas-liquid mass transfer rate was evaluated for short films and reactive conditions, closer to those of interest, which also ensure that both film and slug regions remain contributive throughout the capillary; it was shown that transferred mass flux and average concentration vary with surface reaction rate, but not the relative contribution of film and caps to the overall mass transfer. $\mathrm{k}_{\mathrm{L}} \mathrm{a}$ values close to $0.1 \mathrm{~m}^{3} \mathrm{~L} \mathrm{~m}^{-3} \mathrm{Uc} \mathrm{s}{ }^{-1}$ were obtained for a $3 \mathrm{~mm}$ diameter channel and bubble velocity of $0.3 \mathrm{~m} \mathrm{~s}^{-1}$, in good agreement with the correlation of van Baten and Krishna which was also established for steady state values. Other literature correlations either included the effect of the inlet dissolved gas-depleted zones or were developed for rather different bubble contacting time, leading to larger discrepancies. Despite same hemispherical shape applied for front 
Table 6

Details of simulation results for the kinetic constant dependence.

\begin{tabular}{|c|c|c|c|c|c|c|}
\hline & & Bubble nose & Film & Bubble tail & Total (UC) & Units \\
\hline \multirow[t]{4}{*}{ Case $\left(1^{\prime}\right)$} & Molar Flux & $1.59 \times 10^{-10}$ & $3.48 \times 10^{-10}$ & $3.65 \times 10^{-11}$ & $5.44 \times 10^{-10}$ & {$\left[\mathrm{~mol} \mathrm{~s}^{-1}\right]$} \\
\hline & $\mathrm{c}_{\mathrm{s}, \text { mean }}$ & 1.27 & - & 1.27 & 1.27 & {$\left[\mathrm{~mol} \mathrm{~m}^{-3} \mathrm{~L}\right]$} \\
\hline & $c_{\text {wall }}$ & 1.20 & 1.20 & 1.20 & 1.20 & {$\left[\mathrm{~mol} \mathrm{~m}^{-3} \mathrm{~L}\right]$} \\
\hline & $\mathrm{k}_{\mathrm{L}} \mathrm{a}$ & 0.02 & 0.01 & 0.01 & 0.08 & {$\left[\mathrm{~m}^{3}{ }_{\mathrm{L}} \mathrm{m}^{-3} \mathrm{uc} \mathrm{S}^{-1}\right]$} \\
\hline \multirow[t]{4}{*}{ Case $\left(2^{\prime}\right)$} & Molar Flux & $2.02 \times 10^{-9}$ & $4.41 \times 10^{-9}$ & $4.84 \times 10^{-10}$ & $6.92 \times 10^{-9}$ & {$\left[\mathrm{~mol} \mathrm{~s}^{-1}\right]$} \\
\hline & $\mathrm{c}_{\mathrm{s}, \text { mean }}$ & 0.99 & - & 0.99 & 0.99 & {$\left[\mathrm{~mol} \mathrm{~m}^{-3} \mathrm{~L}\right]$} \\
\hline & $\mathrm{c}_{\text {wall }}$ & 0.06 & 0.06 & 0.06 & 0.06 & {$\left[\mathrm{~mol} \mathrm{~m}^{-3} \mathrm{~L}\right]$} \\
\hline & $\mathrm{k}_{\mathrm{L}} \mathrm{a}$ & 0.02 & 0.01 & 0.01 & 0.08 & {$\left[\mathrm{~m}^{3}{ }_{\mathrm{L}} \mathrm{m}^{-3} \mathrm{UC} \mathrm{S}^{-1}\right]$} \\
\hline \multirow[t]{4}{*}{ Case $\left(3^{\prime}\right)$} & Molar Flux & $2.12 \times 10^{-9}$ & $4.63 \times 10^{-9}$ & $5.08 \times 10^{-10}$ & $7.26 \times 10^{-9}$ & {$\left[\mathrm{~mol} \mathrm{~s}^{-1}\right]$} \\
\hline & $\mathrm{c}_{\mathrm{s}, \text { mean }}$ & 0.97 & - & 0.97 & 0.97 & {$\left[\mathrm{~mol} \mathrm{~m}^{-3} \mathrm{~L}\right]$} \\
\hline & $c_{\text {wall }}$ & 0 & 0 & 0 & 0 & {$\left[\mathrm{~mol} \mathrm{~m}^{-3} \mathrm{~L}\right]$} \\
\hline & $\mathrm{k}_{\mathrm{L}} \mathrm{a}$ & 0.02 & 0.01 & 0.01 & 0.08 & {$\left[\mathrm{~m}^{3}{ }_{\mathrm{L}} \mathrm{m}^{-3} \mathrm{uc} \mathrm{S}^{-1}\right]$} \\
\hline
\end{tabular}

and rear bubble caps, the two zones were not found equivalent in terms of gas transferred rates. The rear bubble zone exhibited, as a consequence of a lower local liquid velocity, a more tepid activity, three to four times lesser than the bubble nose region. Such effect should be accentuated for a more realistic bubble shape (with elongated nose and flattened back) due to significant difference in corresponding surface areas. For the rather short unit cells investigated (with length 4-14 times the capillary diameter), film contribution to mass transfer flux varies in a wider range than usually reported, coming down from 64\% (in the Van Baten and Krishna's reference case) to $20 \%$ when unit cell size is significantly reduced, and pointing out that the approximation based on gas holdup and unit cell length for film length ceases to be a valid approximation.

Further work will examine end effects by simulating several unit cells with open boundary conditions and will extend the parametric study to shorter slugs, longer bubbles, larger capillary numbers and different bubble velocities to assess the relative contribution of bubble/film zones for a wider range of operating conditions.

\section{Acknowledgements}

Authors thank the French agency "Agence Nationale pour la Recherche" for financial support (grant number ANR-12-CDII0011-01), and TOTAL S.A. company for financial and scientific support.

\section{Appendix A. Supplementary data}

Supplementary data associated with this article can be found, in the online version, at http://dx.doi.org/10.1016/j.cattod.2016.04. 009.

\section{References}

[1] J.R. Van Ommen, M.-O. Coppens, M.T. Kreutzer, F. Kapteijn, J.A. Moulijn, AIChE Annual Meeting Conference Proceedings (2004) 10457-10466.

[2] T. Boger, A.K. Heibel, C.M. Sorensen, Ind. Eng. Chem. Res. 43 (2004) 4602-4611.

[3] A.K. Heibel, F.J. Vergeldt, H. van As, F. Kapteijn, J.A. Moulijn, T. Boger, AIChE J. 49 (2003) 3007-3017.

[4] S. Roy, M. Al-Dahhan, Catal. Today 105 (2005) 396-400.
[5] M. Behl, S. Roy, Chem. Eng. Sci. 62 (2007) 7463-7470.

[6] Y. Zhou, M. Al-Dahhan, M. Dudukovic, H. Liu, Chin. J. Chem. Eng. 20 (2012) 693-700.

[7] T. Fukano, A. Kariyasaki, Nucl. Eng. Des. 141 (1993) 59-68.

[8] K. Mishima, T. Hibiki, Int. J. Multiphase Flow 22 (1996) 703-712.

[9] J.W. Coleman, S. Garimella, Int. J. Heat Mass Transfer 42 (1999) 2869-2881.

[10] N. Shao, A. Gavriilidis, P. Angeli, Chem. Eng. Sci. 64 (2009) 2749-2761.

[11] J.J. Heiszwolf, M.T. Kreutzer, M.G. van den Eijnden, F. Kapteijn, J.A. Moulijn, Catal. Today 69 (2001) 51-55.

[12] C.O. Vandu, H. Liu, R. Krishna, Chem. Eng. Sci. 60 (2005) 6430-6437.

[13] K. Kawakami, K. Kawasaki, F. Shiraishi, K. Kusunoki, Ind. Eng. Chem. Res. 28 (1989) 394-400.

14] C.O. Vandu, J. Ellenberger, R. Krishna, Chem. Eng. Sci. 59 (2004) 4999-5008.

[15] J. Yue, G. Chen, Q. Yuan, L. Luo, Y. Gonthier, Chem. Eng. Sci. 62 (2007) 2096-2108.

[16] S. Mehdi, A.-M. Billet, I.R. Chughtai, M.H. Inayat, Asia Pac. J. Chem. Eng. 8 (2013) 931-939.

[17] S. Irandoust, S. Ertlé, B. Andersson, Can. J. Chem. Eng. 70 (1992) 115-119.

[18] G. Berčič, A. Pintar, Chem. Eng. Sci. 52 (1997) 3709-3719.

[19] J.M. van Baten, R. Krishna, Chem. Eng. Sci. 59 (2004) 2535-2545.

[20] N. Shao, A. Gavriilidis, P. Angeli, Chem. Eng. J. 160 (2010) 873-881.

[21] D. Liu, S. Wang, Ind. Eng. Chem. Res. 50 (2011) 2323-2330.

[22] A. Hassanvand, S.H. Hashemabadi, Int. J. Heat Mass Transfer 55 (2012) 5959-5971.

[23] Z. Pan, X. Zhang, Y. Xie, W. Cai, Chem. Eng. Technol. 37 (2014) 495-504.

[24] V. Hatziantoniou, B. Andersson, N.H. Schoon, Ind. Eng. Chem. Process Des. Dev. 25 (1986) 964-970.

[25] T. Nijhuis, M.T. Kreutzer, A.C. Romijn, F. Kapteijn, J.A. Moulijn, Chem. Eng. Sci. $56(2001) 823-829$

[26] M.T. Kreutzer, P. Du, J.J. Heiszwolf, F. Kapteijn, J.A. Moulijn, Chem. Eng. Sci. 56 (2001) 6015-6023.

[27] T. Haakana, E. Kolehmainen, I. Turunen, J.-P. Mikkola, T. Salmi, Chem. Eng. Sci. 59 (2004) 5629-5635

[28] K. Fukagata, N. Kasagi, P. Ua-arayaporn, T. Himeno, Int. J. Heat Fluid Flow 28 (2007) $72-82$.

[29] R. Gupta, D. Fletcher, B. Haynes, J. Comput. Multiphase Flow 2 (2010) 1-32.

30] R. Gupta, D.F. Fletcher, B.S. Haynes, Chem. Eng. Sci. 64 (2009) 2941-2950.

[31] D.A. Hoang, V. van Steijn, L.M. Portela, M.T. Kreutzer, C.R. Kleijn, Comput. Fluids 86 (2013) 28-36.

[32] F.P. Bretherton, J. Fluid Mech. 10 (1961) 166-188.

[33] P. Aussillous, D. Quéré, Phys. Fluids 12 (2000) 2367-2371.

[34] C. Meyer, M. Hoffmann, M. Schlüter, Int. J. Multiphase Flow 67 (2014) $140-148$.

[35] T. Taha, Z.F. Cui, Chem. Eng. Sci. 61 (2006) 676-687.

[36] D. Qian, A. Lawal, Chem. Eng. Sci. 61 (2006) 7609-7625.

37] T.C. Thulasidas, M.A. Abraham, R.L. Cerro, Chem. Eng. Sci. 50 (1995) 183-199.

[38] G.I. Taylor, J. Fluid Mech. 10 (1961) 161-165.

[39] T.C. Thulasidas, M.A. Abraham, R.L. Cerro, Chem. Eng. Sci. 52 (1997) 2947--2962

[40] M.T. Kreutzer, F. Kapteijn, J.A. Moulijn, J.J. Heiszwolf, Chem. Eng. Sci. 60 (2005) 5895-5916.

[41] R.S. Abiev, Theor. Found. Chem. Eng. 42 (2008) 105-117.

[42] P. Sobieszuk, J. Aubin, R. Pohorecki, Chem. Eng. Technol. 35 (2012) 1346-1358. 